\title{
An Optimization Method of Logistics Supply Chain for Supermarket Supply of Fresh Agricultural Products
}

\author{
Xue Min \\ Department of Management, Guangdong University of Science \& Technology, Dongguan, China \\ 17270150@qq.com
}

\author{
Keywords: Supermarket; Fresh Agricultural Products; Supply Chain; Adaptive Path-Finding \\ Model
}

\begin{abstract}
When the supermarket is seen as the core in the supply chain of fresh agricultural products, the distribution center of supermarket is gradually extended to the upstream and the distribution center for processing raw and fresh agricultural products appears. The logistics system and information platform are improved through the advanced electronic information technology in the process of trading and distribution of fresh agricultural products, which make it gradually become an important link closely with the production and retail. The management of supply chain has greatly depended on modern information technology. Through the current situation, it can be seen that the supermarkets have already possessed certain information level and can realize standardized management of commodities. However, there are still some shortcomings in the supply chain of fresh agricultural products supplied by supermarkets, and it is urgent to optimize the supply chain management. This paper mainly analyzes the characteristics of supply chain management of fresh agricultural products, and then studies the current situation of supermarket supply chain management of fresh agricultural products, and finally puts forward the optimization method of the supply chain management of fresh agricultural products in supermarket.
\end{abstract}

\section{Introduction}

At present, the supply chain of fresh agricultural products in supermarkets has not yet produced a reasonable distribution system. It is known that the supermarket operators is paying more and more attention to the operation of fresh agricultural products through the investigation, but it is not profitable at present[1]. The gross profit of fresh agricultural products in foreign supermarkets is about $20 \%$ and only $0-10 \%$ in China. On the one hand, the reason for this phenomenon is the consumption level and habits of our people. On the other hand, the supermarket supply chain system has not yet been generated, which directly increases the operation cost of fresh agricultural products. At the same time, it does not meet the established standard in terms of price and quality.

The characteristics of supply chain management of fresh agricultural products are shown as follows. The supply chain is long, and the links of each link are not smooth[2-3]. Fresh agricultural products has many types and the supply chain of each ring node formed a large number of members, so the increased chain will increase the cost, and the members in each sector are hoped to reduce costs and obtain the highest economic benefit. As a result, the invisible factors increase the cost and reduce profits, which is easily lead to quality supervision.

The supply chain management system is lack of perfection. Under current supply chain environment of fresh agricultural products, the enterprise does not run a certain part of the supply chain link according to the relevant system[4-5]. For example, in the procurement process, because the market price is significantly more than the price of the order, the supplier provides goods with a higher bidder in violation of the regulations in order to gain greater profits. On the other hand, purchasers may also be in violation of the agreement to compress the number of acquisitions[6]. The situation will also appear in other links, so the emergence of these conditions should be avoided and the mechanism of supply chain management should be urgently needed to carry out. 


\section{Comprehensive Evaluation Model of the Logistics Supply Chain}

The Corresponding Evaluation Factor. The correlation degree analysis method in logistics supply chain system theory is a new quantification method to measure the correlation degree of measurement factors[7-9] and it is a comparison for the relationship of statistical data lists. In this paper, the correlation analysis method has been employed to establish the comprehensive evaluation model with the least squares criterion.

Assuming that there are $m$ evaluation objects in the system and each object has $n$ evaluation factors. The composition of attribute value of each evaluation object in the corresponding evaluation factor is shown in the attribute matrix in formula (1).

$$
X=\left[\begin{array}{cccc}
x_{11} & x_{12} & \cdots & x_{1 n} \\
x_{21} & x_{22} & \cdots & x_{2 n} \\
\cdots & \cdots & \cdots & \cdots \\
x_{m 1} & x_{m 2} & \cdots & x_{m n}
\end{array}\right]=\left(x_{i j}\right)_{m \times n}
$$

In formula (1), $x_{i j}$ represents the index attribute value of the $i$ th evaluation object in the $j$ th evaluation factor. In this paper $n=4, m=12$ and the element is the data value of corresponding item, then $X=\left(x_{i j}\right)_{1 \times 4}$.

The normalized matrix can be understood as the matrix after data standardization[10]. The calculation methods are shown in formula (2), (3) and (4).

$$
\begin{aligned}
& x_{i j}^{*}=\frac{x_{i j}-\min x_{i j}}{\max x_{i j}-\min x_{i j}} \\
& x_{i j}^{*}=\frac{\max x_{i j}-x_{i j}}{\max x_{i j}-\min x_{i j}} \\
& x_{i j}^{*}=1-\frac{\left|x_{i j}-\gamma_{i}\right|}{\max \left|x_{i j}-\gamma_{i}\right|}
\end{aligned}
$$

In formula (2), (3) and (4), $x_{i j}^{*}$ represents the matrix element after standarization and $0 \leq x_{i j}^{*} \leq 1$. In formula (4), $\gamma_{i}$ refers to the standard value of the $i$ th object.

Correlation Degree Analysis. The data normalization processing of factors has been used to get the weight vectors of evaluation factors, which is shown in formula (5).

$$
\vec{W}=\left(\omega_{1}, \omega_{2}, \cdots, \omega_{n}\right), \sum_{i=1}^{n} \omega_{i}=1
$$

In this paper, $n=3$. The correlation degree measurement between number sequences is shown in the form of correlation coefficients. The correlation coefficient of the $j$ th scheme vector $\vec{X}_{j}$ and the optimal vector $\vec{G}$ is shown in formula (6).

$$
\xi_{i}\left(\vec{X}_{j}, \vec{G}\right)=\frac{\min _{j} \min _{i}\left|x_{i j}^{*}-g_{i}\right|+r \max _{j} \max _{i}\left|x_{i j}^{*}-g_{i}\right|}{\left|x_{i j}^{*}-g_{i}\right|+r \max _{j} \max _{i}\left|x_{i j}^{*}-g_{i}\right|}
$$


In formula (6), $\xi_{i}\left(\vec{X}_{j}, \vec{G}\right)$ refers to the correlation coefficient and $r$ refers to the resolution coefficient and $r \in[0,1]$. The correlation coefficient of the $j$ th scheme vector $\vec{X}_{j}$ and the sub vector $\vec{B}$ is shown in formula (7).

$$
\xi_{i}\left(\vec{X}_{j}, \vec{B}\right)=\frac{\min _{j} \min _{i}\left|x_{i j}^{*}-b_{i}\right|+r \max _{j} \max _{i}\left|x_{i j}^{*}-b_{i}\right|}{\left|x_{i j}^{*}-b_{i}\right|+r \max _{j} \max _{i}\left|x_{i j}^{*}-b_{i}\right|}
$$

The correlation degree between $\vec{X}_{j}$ and optimal vector $\vec{G}$ as well as $\vec{X}_{j}$ and sub vector $\vec{B}$ is shown in formula (8).

$$
\left\{\begin{array}{l}
v\left(\vec{X}_{j}, \vec{G}\right)=\sum_{i=1}^{n} \omega_{i} \xi_{i}\left(\vec{X}_{j}, \vec{G}\right) \\
v\left(\vec{X}_{j}, \vec{B}\right)=\sum_{i=1}^{n} \omega_{i} \xi_{i}\left(\vec{X}_{j}, \vec{B}\right)
\end{array}\right.
$$

\section{The Optimal Result of Supply Chain Management of Fresh Agricultural Products in Supermarkets}

The optimization results set up a perfect supply chain system for fresh agricultural products and realized information sharing. Information interconnection is the basis for improving supply chain. When fully ensuring the participants' information communication in supply chain management, the construction of electronic management system is relatively perfect based on the good communication between suppliers, supermarkets and consumers. It completed the online orders and signed a cooperation to control all aspects of payment procedures. All data from order are accurately listed for the settlement of the sales process to avoid unnecessary conflicts between suppliers and supermarkets. In addition, a communication medium between supermarket managers and suppliers is also established, which ensures the healthy competition between suppliers and accurately selects the best suppliers.

The rules of the information push adaptive path-finding model are as follows: The node initiates a path seeking request and is forwarded to the neighbor node according to the pheromone table. The neighbor node receives the request and checks whether it contains the information of the resource item. If routing is successful, back tracking the pheromone. If not, the peer status is obtained from the pheromone table of the node, and whether the source node can be cloned is obtained. If yes, a corresponding number of routing peers are dynamically cloned and an appropriate value is obtained, which is forwarded to different neighbors of high pheromone concentration. Each routing peer keeps some contact with the original requesting node. On the one hand, it is convenient to clone more peers that need to be traversed at the right time; on the other hand, the entire peer group can be ended when one peer is successful. The successful path sends back the target information through the successful peer and updates the pheromone and list of the entire path by updating the peer.

Comparison of the evaluation results of traditional logistics supply chain and constructivist logistics supply chain are shown in Fig. 1. 


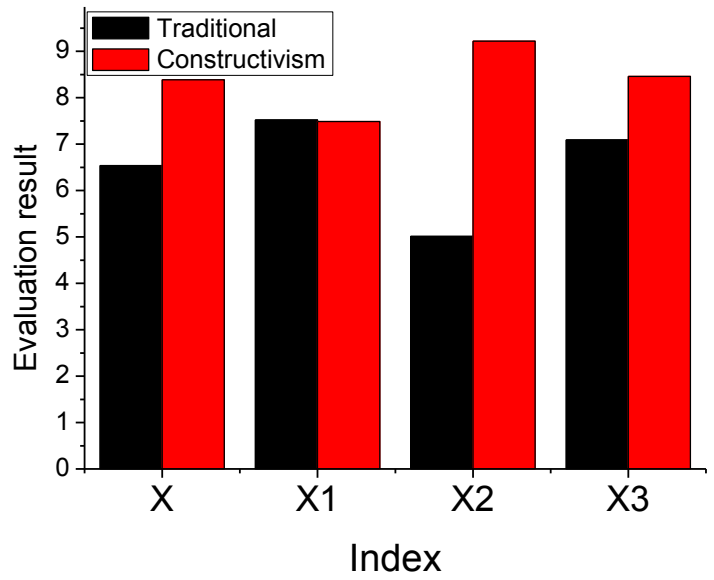

Figure 1. Finite Comparison of the evaluation results of traditional logistics supply chain and constructivist logistics supply chain

The changes of logistics supply chain in the static panel regression are shown in Fig. 2.

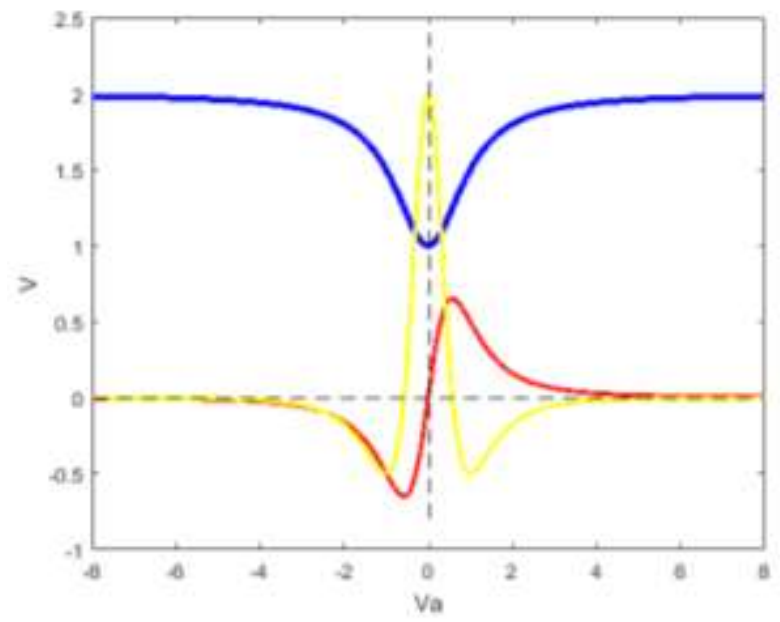

Figure 2. Finite The changes of logistics supply chain in the static panel regression

\section{Summary}

A comprehensive analysis shows that supermarkets already have certain economic strength so that the supply chain of fresh products will be further improved, and the quality of products will be further improved so as to meet the needs of consumers to a large extent. All employees can attach importance to supply chain management. Optimization of supply chain of fresh agricultural products in supermarkets not only improves the shopping environment and food safety and ensures the processing quality of agricultural products, but also improves the competitiveness.

\section{References}

[1] Erdogan, S., Ilçi, V., and Soysal, O. M., A model suggestion for the determination of the traffic accident hotspots on the turkish highway road network: A pilot study, British Journal of Haematology. 21 (2015) 69-188.

[2] Connors, R. D. and Watling, D. P., Assessing the Demand Vulnerability of Equilibrium Traffic Networks via Network Aggregation, Psych Nology Journal, 15 (2015), 367-395.

[3] Hong, K. L., and Szeto, W. Y. Time-dependent transport network design under cost-recovery, Transportation Research Part B Methodological, 43 (2009), 142-158. 
[4] Sharma, S., and Mathew, T. V., Ukkusuri, S. V. Approximation Techniques for Transportation Network Design Problem under Demand Uncertainty, Journal of Computing in Civil Engineering, 25 (2011), 316-329.

[5] Kuang, H., Kilgour, D. M., and Hipel, K. W. Grey-based PROMETHEE II with application to evaluation of source water protection strategies. Information Sciences, 294 (2015), 376-389.

[6] A. Ravenscroft, A. Schmidt, J. Cook, C. Bradley. Designing Social Media for Informal Learning and Knowledge Maturing in the Digital Workplace, Journal of Computer Assisted Learning, 28 (2012), 112-120.

[7] JY Nancy, NH Khanna, K Arputharaj. A Q-back propagated time delay neural network for diagnosing severity of gait disturbances in Parkinson's disease, Journal of Biomedical Informatics, 60 (2016), 169-176.

[8] BBC Onwuagboke, and TKR Singh, Effects of Computer Self-Efficacy on Pre-Service Art Teachers' Achievement in Graphic Design, Pertanika Journal of Social Science \& Humanities, 24 (2016), 1315-1333.

[9] BR Webb, SB Gallagher. Mapping Commonalities and Differences in Software Engineering and Graphic Design Approaches to Multimedia Systems Development, Journal of Computer Information Systems, 46 (2016), 87-98.

[10] S Laing, and M Masoodian. A study of the influence of visual imagery on graphic design ideation, Design Studies, 45 (2016), 187-209. 